\title{
A computer programming hybrid MOOC for Greek secondary education
}

\author{
Philippos Koutsakas ${ }^{1 *}$ (D), Charalampos Karagiannidis ${ }^{1}$, Panagiotis Politis ${ }^{2}$ and Ilias Karasavvidis $^{3}$
}

\footnotetext{
* Correspondence: fkoutsakas@uth.

'Department of Special Education, University of Thessaly, Volos, Greece Full list of author information is available at the end of the article
}

\begin{abstract}
The present paper presents the planning, implementation, observation and analysis of both quantitative and qualitative data of a participatory action research, aiming to study the potential role, value and uses of MOOCs in secondary education. Within the context of this research, a computer programming hybrid MOOC (named PROG15) which combined aspects of both $x$ - and c-MOOCs architecture and pedagogy was designed, implemented and openly provided to Greek Secondary Education students.

The MOOC completion rate (xMOOC dimension) was relatively low, but similar to that of typical XMOOCs for adults, while the degree of collaboration with other students and contribution to the course content (the cMOOC dimension) was relatively average. Before their involvement in the $\mathrm{MOOC}$, the participating students recorded particularly high learning expectations from the specific course and from the collaborative learning model it proposed and quite positive views regarding the impact of this new educational tool on secondary education. Their attitude towards these issues was even more positive after their involvement in the MOOC, while their overall experience was particularly positive.

The above findings, although they resulted from a comparatively small sample of students for the measures of MOOCs and within a very specific educational context, they form a particularly promising background for the utilization of this new tool in secondary education in general and specifically for the preparation of students for higher education studies, in subjects related to computer programming. Of course, further research and investigation is required on the design, development and implementation of the next generation of MOOCs and the practical and theoretical research outcomes resulted from this research can be a quite valuable input.
\end{abstract}

Keywords: MOOCs, Secondary education, K-12, Computer programming

\section{Introduction}

Massive open online courses - MOOCs are online courses aiming at unlimited participation and open access to knowledge via the web (Kaplan \& Haenlein, 2016). They first appeared in 2008, emerging from the Open Educational Resources movement (Liyanagunawardena, Adams, \& Williams, 2013), when Siemens, Downes and Cormier developed the course "Connectivism and Connective Knowledge - CCK08" that succeeded to attract more than 2200 students worldwide (Downes, 2008) and it has since become known as the first MOOC.

(c) The Author(s). 2020 Open Access This article is distributed under the terms of the Creative Commons Attribution 4.0 International License (http://creativecommons.org/licenses/by/4.0/), which permits unrestricted use, distribution, and reproduction in any medium, provided you give appropriate credit to the original author(s) and the source, provide a link to the Creative Commons license, and indicate if changes were made. 
Since then, an increasing number of the most recognizable higher education institutions incorporated MOOCs as a mean of delivering and certifying knowledge, aiming to provide higher education learning opportunities more broadly, to promote lifelong learning and to widen participation. Nowadays, it is estimated that more than 13.5 thousand of such courses, provided free and open educational content to more than 110 million learners worldwide (Class Central, 2019a), establishing one of the most active areas in the field of open, distance and electronically supported learning. The provided courses which cover a wide range of learning objects, are accessible to anyone interested, regardless of age, prior educational experience or academic degrees.

This growing trend on MOOCs began to touch educational levels lower than those of higher education only after 2013 (Yin, Adams, Goble, \& Madriz, 2015; Atkeson, 2014) when the first K-12 MOOCs were provided through independent initiatives untaken by well-respected universities, educators and researchers. Most of these initiatives aimed to facilitate and support high-school graduates in their decision and preparation for post-graduate studies (Edx, 2018; FutureLearn, 2018). Canvas, European SchoolNet Academy, FurureLearn, Coursera and Edx platforms hosted these courses for younger audiences and $\mathrm{K}-12$ educators.

Research on MOOCs utilization in K-12 education started to appear in the literature only after 2013 (Ferdig, 2013) but till nowadays the peer reviewed research available on this area remains scarce (Koutsakas, 2018). Therefore, the perspectives, the educational value and dangers resulting from the utilization of this quite promising learning tool in the sensitive area of K-12 education and its potential role and uses require further research and exploration.

The purpose of this research is to contribute to the exploration of this quite promising research area, focusing on the perspectives of MOOCs' utilization in K-12 education. More specifically, this paper emphasizes on students' motives, expectations and attitudes from their participation in a K-12 MOOC, as well as, on the parameters that affect students' completion rate, involvement, interaction with their fellow students and contribution to the course.

The rest of the paper is structured as follows: in Section 2 we discuss the required background information for MOOC taxonomies, computer programming MOOCs, as well as, for MOOCs developed for K-12 education and we present the focus of the research. Section 3 presents the proposed methodology, including the planning, implementation, observation, data collection and analysis phases. Section 4 presents the analysis of the collected results and the conclusion of this work, while Section 5 proposes areas for further research and exploration in the field.

\section{Background MOOC taxonomies}

Despite the many different proposed taxonomies for MOOCs, the c- and xMOOCs remain the most common way that researchers use to categorize MOOCs, together with hybrid MOOCs (h-MOOCs) that incorporate aspects from both c and x MOOC types (Conole, 2014; Fidalgo-Blanco, Sein-Echaluce, \& García-Peñalvo, 2016; Pilli \& Admiraal, 2016).

The $\mathrm{c}$ in cMOOCs stands for connectivity or connectivism and as a result these MOOCs are "based on principles of connectivism, openness, and participatory teaching" 
(Jacoby, 2014, p. 76), put emphasis on students constructing their knowledge, creativity, autonomy and collaborative learning and "[focus on] human agency, user participation, and creativity through a dynamic network of connections afforded by online technology" (Ebben \& Murphy, 2014, p. 333). In a cMOOC environment, the participants share information and actively engage in a teaching-learning experience through technologymediated communications, while learning happens through dialogue, interaction, and exploration.

Early MOOCs tended to follow the cMOOC model, whereas more recently the number of xMOOCs delivered has been growing rapidly and nowadays, the most famous type of MOOCs are the xMOOCs. By contrast, xMOOCs are described as "follow [ing] a cognitivist-behaviorist approach" (Hew \& Cheung, 2014, p. 50) and resemble "traditional teacher-directed course [s], yet automated, massive, and online" (Kennedy, 2014, p. 8). The learning content of $x M O O C s$ is organized around a central instructor and a core curriculum which mainly consists of pre-recorded video lectures and quizzes, with no emphasis in networking but instead on the transfer of knowledge from the teacher to the student (Conole, 2013; Siemens, 2012). In this respect, participating students, while following their own pace, remain passive. Usually, xMOOCs gather a vast amount of data by tracking participants, which are then processed and analyzed in the light of student behavior with the aim to better understand the teaching/learning process (Bayne \& Ross, 2014; Kesim \& Altınpulluk, 2015).

Apart from $\mathrm{x}$ and cMOOC models Fidalgo-Blanco et al. (2016) proposed a hybrid model which incorporates aspects from both c- and xMOOC types (see Fig. 1). The proposed model is based on the use of a specific e-learning platform for formal training (the $\mathrm{x}$ - dimensions of the $\mathrm{MOOC}$ ) and a social network for informal training (the c- dimension of the MOOC). Formal and non-formal learning activities (in the $\mathrm{x}$ - platform) are combined with informal learning (in the c- platform) and cooperation among participants to generate a continuous flow of knowledge between platforms.

The e-learning platform (the $\mathrm{x}$ - dimension) of hMOOCs contains a set of resources developed by the instructor and organized in modules and sections which are available

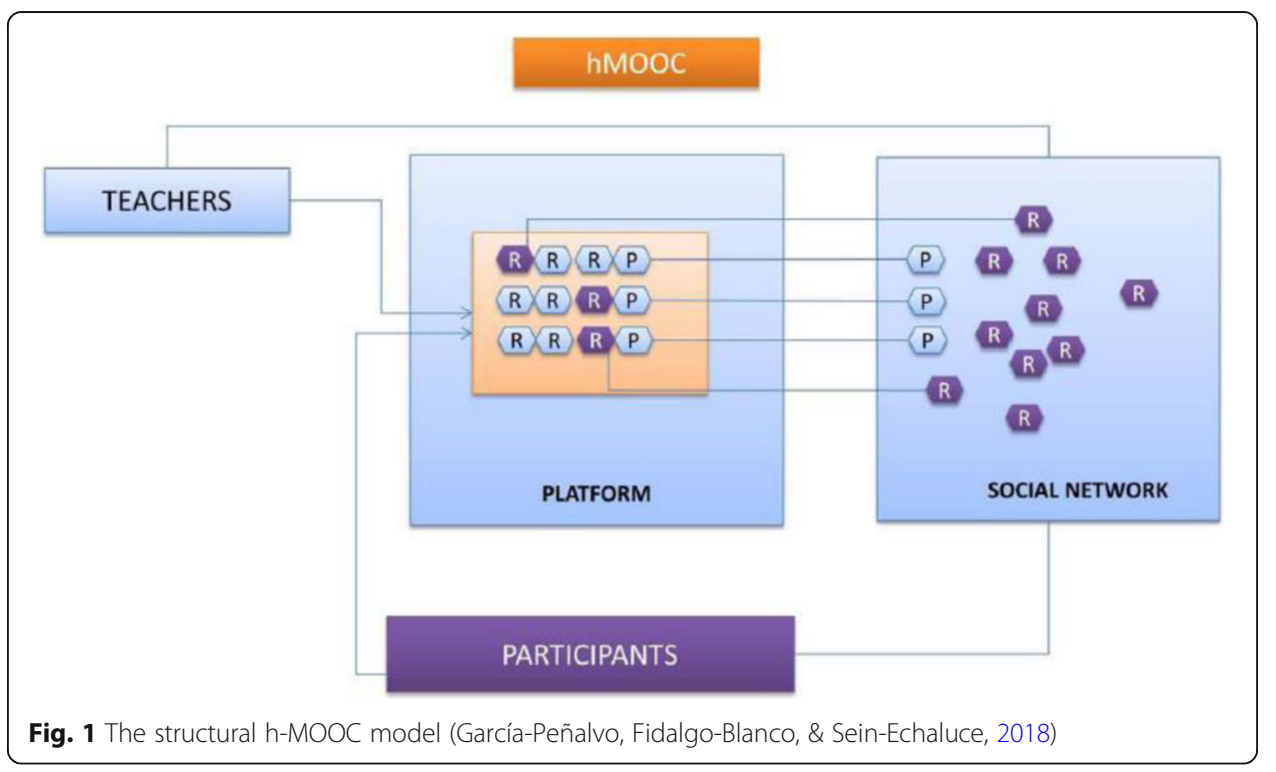


for passive consumption/attendance. On the other hand, participants can generate learning resources in the social network (the c- dimension) of the hMOOC which can be shared and incorporated in the MOOC and used by other students.

Previous studies on hMOOCs (Fidalgo-Blanco et al., 2016) have shown that the rate of completion is higher for this model and it is widely accepted by participants.

\section{Computer programming MOOCs}

Over the past few years there has been a growing interest in promoting and teaching computer programming to a worldwide audience through MOOCs (De Kereki \& Manataki, 2016). As a result, a plethora of introductory computer programming MOOCs can be found in well-established MOOC platforms.

For example, in December 2019, an advanced search in the edx MOOC platform using the term "computer programming" returned 446 computer programming related courses, 682 computer programming related courses in Coursera, 2513 courses in Udemy, 53 in Udacity and 23 courses in Future Learn. Additionally, in the list of the top 100 MOOCs of all time (Class Central, 2019b), 14 MOOCs are courses related to teaching/learning computer programming, which means that computer programming MOOCs hold a central role in the area of open, distant and on-line learning not only in terms of quantity, but in term of quality, too.

The majority of these courses attempt to teach professional programming languages, mostly targeting to adults, higher education students or life-long-learning professionals (Ben-Ari, 2013; Guzdial \& Adams, 2014).), while there is a scarcity of computer programming MOOCs that are addressed to children and teenagers. This leaves an important gap and reveals the need to develop computer programming MOOCs for young audiences, especially if we take into consideration the identified need to equip the new generation with coding and computational thinking skills (Balanskat \& Engelhardt, 2014).

\section{Research on $\mathrm{K} 12$ MOOCS}

After the appearance of the first K12 MOOCs on 2013, a small but increasing through time number of academic papers appeared in the peer reviewed literature, attempting to evaluate the effects of MOOCs utilization in K-12 education. Most of these research works focused on topics related to (a) learners and learning process (student-focused), while fewer papers dealt with (b) teachers/instructors (teacher-focused) and (c) MOOCs design and development (design-focused).

The student-focused research identified that K12 MOOCs can support young students through the provision of valuable content and different learning strategies/styles and can contribute to a positive change on education in general (Brahimi \& Sarirete, 2015; Grella, Staubitz, Teusner, \& Meinel, 2016; Koutsakas, 2018; Nigh, Pytash, Ferdig, \& Merchant, 2015; Holotescu et al, 2014). The integration of MOOCs in compulsoryage education was found to have positive results (Filvà, Guerrero, \& Forment, 2014) either in self-study approaches (Najafi, Evans, \& Federico, 2014) or by using the benefits of guided learning (Khalil \& Ebner, 2015). In some MOOC implementations of schoolbased courses, students scored better in the MOOC version than the face-to-face version of the course (Canessa \& Pisani, 2013; Grover et al., 2014). 
Additionally, research has shown that K12 students' participation in MOOCs can change the traditional modality of study and systematically improve students' scores (Canessa \& Pisani, 2013), that MOOCs have a positive impact on compulsory education students' learning (Brahimi \& Sarirete, 2015 Briggs \& Crompton , 2016) and that MOOCs were proved to be successful for providing supplementary tutoring for students which required learning recovery (Dal Magro et al., 2017). On the other hand, researchers must put more emphasis on the commercial model of MOOCs, in order to attract private initiatives with the aim to fund the development of such MOOCs (Koxvold, 2014).

As far as the motivation level of $\mathrm{K}-12$ students is concerned, the analysis of conducted research on K-12 MOOCs identified that there are both external and internal motivating factors for students to enroll and actively participate in a $12 \mathrm{MOOC}$, with varying outcomes of the course interactions and experiences (Koutsakas, 2018; Nigh et al., 2015). Additionally, Yin et al. (2015) found that MOOCs provide young students with learning experiences that they would not have the opportunity to acquire in other educational environments.

The teacher-focused research on K12 MOOCs showed that teachers (with or without previous experience on MOOCs) are either passionate or demonstrate significant interest regarding the MOOC integration in high school curricula in general (Koxvold, 2014) or in specific subjects like STEM (Dziabenko \& Adorno, 2017) and that they managed to successfully utilize these courses in-class as well as in-school and at-home extracurricular settings (Staubitz, Teusner, \& Meinel, 2019). On the other hand, Grella et al. (2016) identified that teachers are still dubious concerning the integration of such technologies in the school timetable. As the research has shown, these obstacles can be overcome through motivating reports and innovative projects in conjunction with the development of MOOCs for teacher training or Continuing Professional Development (CPD) projects regarding the usage of innovative digital tools and how to effectively incorporate them into their classes (Grella et al., 2016; Koxvold, 2014; Bali, 2013). Teachers involved in such projects have received MOOCs very positively and perceive them as an element that enriched their education (Staubitz et al., 2019). The results of teacher-focused studies (Ferdig, Pytash, Merchant, \& Nigh, 2014; Kilde, Bennett, Gonzales, \& Sterling, 2013) have explicitly shown that these initiatives do work, have positive outcomes, get teachers to think more deeply about teaching and learning in the 21rst century and help them to be more effective in their teaching approach.

The design-focused research on K12 MOOCs showed that the integration of MOOCs in pre-tertiary education requires technical support, ways to increase student motivation of learning in the world of MOOCs, changes in the way schools and teachers face the educational process and also changes in the legal framework conditions in regard to students' data privacy (Grella et al., 2016; Khalil \& Ebner, 2015; Koutsakas, 2018; Koxvold, 2014). Additionally, the conducted research proposed the design of shorter MOOCs in order to increase the completion rate, the use of badges of accomplishments in order to encourage students that participate in MOOCs (Khalil \& Ebner, 2015; Koxvold, 2014) and the utilization of social media for promoting interaction, collaboration and contribution to the course (Koutsakas et al., 2019). 


\section{Focus of our research}

Despite their small number, the above research findings on the resulted benefits from MOOCs' utilization in K-12 education were particularly positive, not only in relation to pre-tertiary education students but also to K12 teachers' professional development. It is obvious that this quite positive but rather small body of research requires further research and exploration in order to question, test and strengthen the till today identified results, to open up new perspectives and to form new approaches to the current state of MOOCs' utilization in pre-tertiary education.

To this extend, the present work aspires to contribute to the efforts for the identification "of MOOC's potential role, value, uses and prospects as a supplementary tool to traditional teaching of a course, taught in Greek secondary education and examined in national exams for entering Greek higher education".

In order to address the above, research question, the present work:

- designed, developed, implemented and openly provided a computer programming MOOC to Greek secondary education students and

- systematically observed, recorded and analyzed the above process, focusing on students' motives for participation, learning expectations, experience from their participation in the MOOC, reasons for early MOOC drop-out, behavior during the participation period and attitudes toward MOOCs after their involvement in the course.

The above process aimed to contribute data for addressing the following more focused research questions:

1. What were secondary education (hence SE) students' motives/reasons for enrollment to the MOOC and reasons for early dropout?

2. What were SE students' learning expectations from their participation in the MOOC and from the collaborative learning model it proposed?

3. How was SE students' overall experience and satisfaction from their participation in the MOOC?

4. What parameters affected SE students' participation in the course, interaction with their fellow students and contribution to the course content and learning resources?

5. What were SE students' attitudes towards the role that MOOCs' can play in secondary education?

The above challenging research questions, in combination with the absence of a standardized educational framework for distance learning in Greek secondary education, makes research on MOOCs' role in this specific educational level even more important and at the same time quite challenging.

\section{Methodology}

The present work aimed at the collection, analysis and contribution of new research data on the potential role, value and prospects of MOOCs in secondary education, aiming to provide new findings in this quite promising research area. 
To achieve the aforementioned research goal, a participatory action research design was utilized, as according to O'Brien (2001) Action Research seems to be ideal to be used by social scientists for "preliminary or pilot research, especially when the situation is too ambiguous to frame a precise research question", or it can be successfully used "to replicate or add to an experience that works well". Additionally, action research, according to Kemmis and McTaggart (1992), can successfully support a goal like this, as a rigor methodology that can be used "for getting better understanding of a situation or a phenomenon through a recursive process of planning, acting, observing and reflecting more carefully, more systematically and more rigorously than one usually does in everyday life".

Under this scope, a four phase participatory action research design was implemented to involve students of the Greek secondary vocational education in a hybrid MOOC (hMOOC) with a teaching subject of this level. As it is demonstrated in Fig. 2, the research was implemented during the 2014-2015 school period and included four stages: (a) planning of the research (b) implementation of the MOOC which was named PROG15 (c) run and observation of the PROG15 MOOC and (d) analysis of the results, with the results of each stage giving feedback to the next stage. The resulted outcomes of PROG15 formed the input data for a new, improved version of the MOOC, named PROG16 which was offered during 2016.

In this paper we will present the planning process of our research, the implementation, observation and analysis phases and we will close by presenting the identified research findings and conclusion, as well as our plans and suggestions for further research.

\section{Planning and implementation phase}

During the planning \& implementation phase of the utilized action research design (09/2014-04/2015) a computer programming MOOC was designed and implemented. The MOOC was named "PROG15 - Computer Programming: preparing for the national exams for tertiary education".

The teaching subject of PROG15 MOOC was computer programming, that is a course included in the curriculum of the 3rd grade of vocational high schools (Greek Ministry of Educations, 2015a) and it is one of the four courses that are

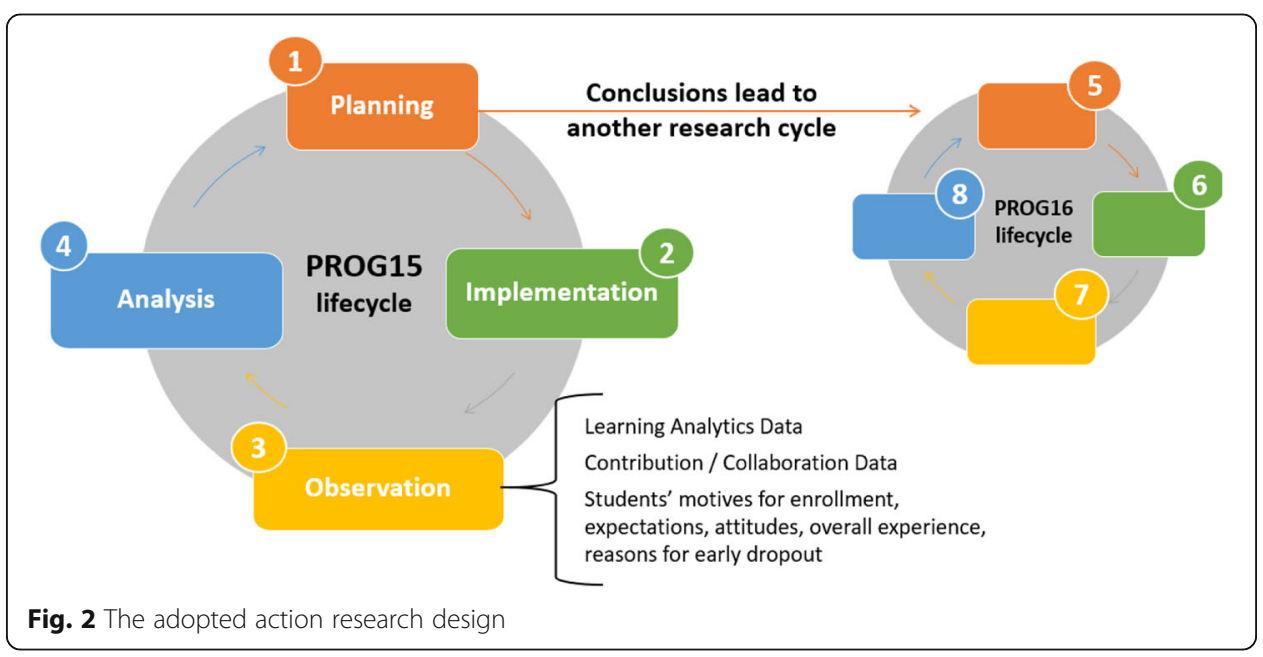


examined in national exams for entering Greek higher educational institutes. The main educational goal of PROG15 was to support students of 3rd grade of Greek Vocational Schools in their preparation for the national exams on computer programming.

The PROG15 utilized a hybrid architecture (hMOOC) that combined elements from both c- and xMOOC approaches. In this respect, as it is shown in Fig. 3, PROG15 MOOC was based upon two pillars/dimensions:

1. the xMOOC dimension, which was hosted in the Udemy platform (https://www. udemy.com/domprogepal/) and provided computer programming learning resources in the form of videoconferences, e-books, exercises, examples, tests, links for further reference and

2. the cMOOC dimension, which was hosted in two asynchronous collaboration platforms (a) the Q\&A forum (https://www.udemy.com/course/domprogepal/) of the Udemy platform and (b) a Facebook Group (https://www.facebook.com/ groups/domprogepal/), which was created for PROG15 and was openly available.

PROG15 attempted to combine formal and non-formal learning activities (in the x- platform) with informal learning and cooperation among participants (in the c- platform), aiming to generate a continuous flow of knowledge amongst participants in both platforms.

PROG15's syllabus included and organized both the educational resources and the collaboration/learning activities in 32 Lectures which were grouped in 9 Sections. Sections 1 and 2 presented an outline of PROG15 content and its goals, its structure, organization and duration and the learning methods and tools to be used. Additionally, they explained participants' obligations and the types of questions posed in previous national exams. Sections 3, 4, 5 and 6 presented step by step the process of analyzing and solving the four different types of computer programming exercises of past national exams. Section 7 attempted a prediction on the

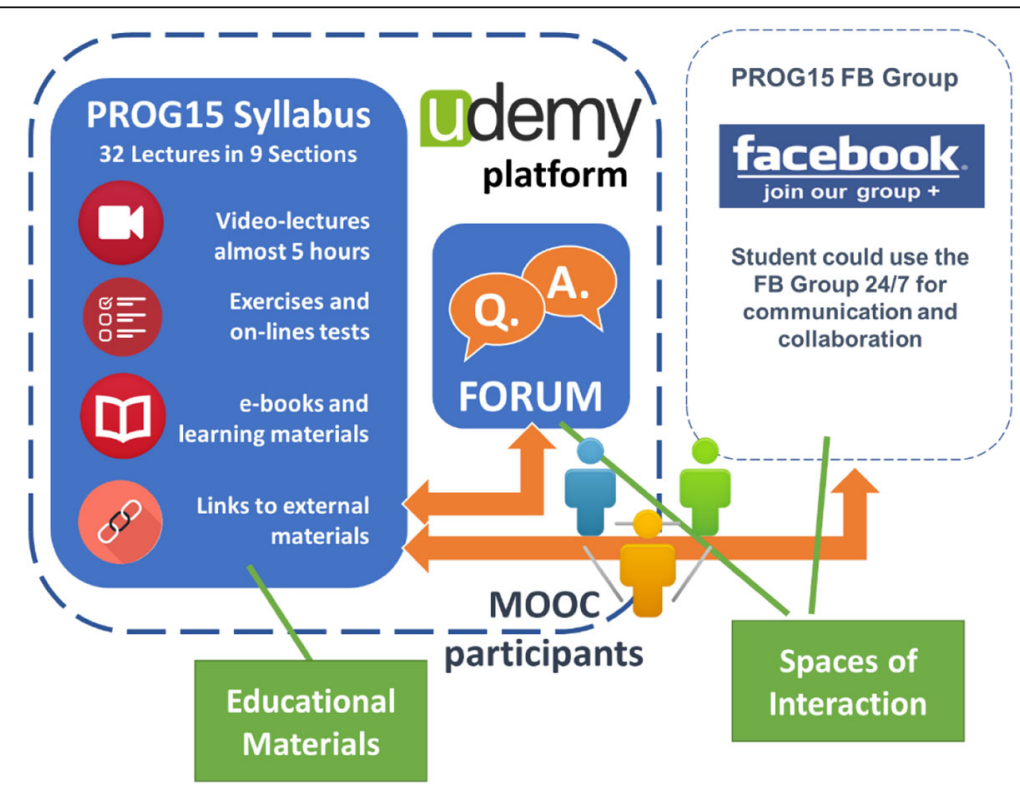

Fig. 3 Components of PROG15 MOOC 
questions of the 2015 exams, while Sections 8 and 9 offered additional resources for revision. The above mentioned structure of the program was based on the one hand on the typical curriculum developed by the Greek Pedagogical Institute for teaching Computer Programming in typical Greek Vocational school classrooms (Greek Ministry of Education, 2015a) and on the other hand, on a comparative analysis of the past questions which were examined in the national exams from 2009 to 2014.

The PROG15 was launched on the 27th of April 2015, six weeks before the national exams on Programming and was offered as an organized MOOC for 7 weeks, until the 14th of June 2015. During this period, the researcher logged in PROG15 on a daily basis both in the MOOC platform and in PROG15's Facebook group in order to observe and support the learning process, to answer students' questions and promote their active participation and contribution to the course. The time he devoted to this process was $10-15 \mathrm{~h}$ per week.

The educational resources of PROG15 were gradually "unlocked" for the students. More specifically, during the first week of the course, only Lectures 1-13 were accessible from the students. The following 8 Lectures were "unlocked" during the second week and the remaining Lectures during the third week. This gradual release of PROG15's educational resources aimed at reinforcing students' co-operation within the two collaboration platforms of PROG15 (Facebook Group and Udemy Q\&A forum) as it forced students to study the same learning resources simultaneously, solve the same exercises and consequently face potentially similar difficulties in which they would be able to support each other.

Every week, PROG15 students were being advised to participate in both $\mathrm{x}$ and cMOOC activities (see Fig. 4). More specifically, students were asked to attend a specific set of Lectures (xMOOC activity), solve and submit to the collaboration platforms the exercises that related to these Lectures ( $\mathrm{x}-\mathrm{MOOC}$ activity) and actively participate in the discussion that followed (cMOOC activity). The time required (from the students' side) in order to fulfill these tasks was 5-7 h per week.

Furthermore, PROG15 students were asked to anonymously reply into two electronic (Google Form) questionnaires, one before and one after their participation in the MOOC. The questionnaires recorded their expectations, attitudes and overall experience regarding MOOCs and PROG15, while during the provision period of PROG15 (7 weeks), learning analytics data were collected for the participating students from Udemy and Google Analytics.

Finally, students' contribution to PROG15 learning resources through their posts and comments in the two collaboration platforms (Udemy Q\&A Forum and FB Group), as well as students' interaction with their fellow students through their comments on their

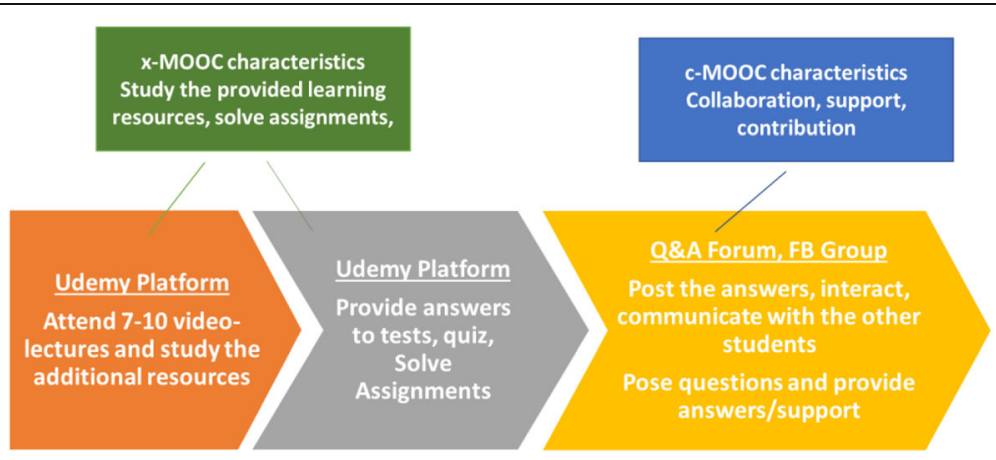

Fig. 4 A typical PROG15 week 
fellow students' posts/comments, were recorded by Grytics (https://grytics.com/) and SocioGraph.io (https://sociograph.io/) platforms, for a period of 12 weeks.

\section{Observation, collection and analysis of results \\ Enrollment in PROG15 (the XMOOC dimension)}

Students' enrollments (number and distribution through time) and completion (percentage of the provided learning resources and rate) are the most common data collected and analyzed in typical higher education MOOCs (Jordan, 2014). Enrollment, according to Jordan (2014) who analyzed the enrollment data for 91 MOOCs, is the process during which a student enrolls in a MOOC for a specific time period. For PROG15 MOOC this period was the time period of 7 weeks during which the PROG15 was offered with the support of the researcher.

During this period, 291 students enrolled in the PROG15, most of whom were students from different Greek vocational schools, while several teachers also registered for the course as well. Despite the relative low number of participants, compared to the thousands of participants in higher education MOOCs, PROG15 can be considered to be massive given that in the Greek national exams of computer programming for that year participated 2.382 students in total (Greek Ministry of Education, 2015b). This practically means that PROG15 succeeded in attracting $12.2 \%$ of the overall population the course aimed to attract.

Distribution of students' enrollments during the 7 weeks of PROG15, was not smooth, recording many more enrollments during the first week of the course and clearly fewer in the weeks that followed (see Fig. 5). More specifically, the course started with quite a small number of pre-registered students ( 28 students had registered before the first day) while the number skyrocketed to 139 only 3 days later, while in the following days the new enrollments ranged from 1 to 6 per day. Exceptions to this enrollment rate are the 4th and 8th of May when PROG15 was advertised in emailing lists and websites for Computer Science teachers and the eve (04/06) of national exams on Programming. According to the Udemy analytics platform the total number of enrolled students during this period of 7 weeks was 291.

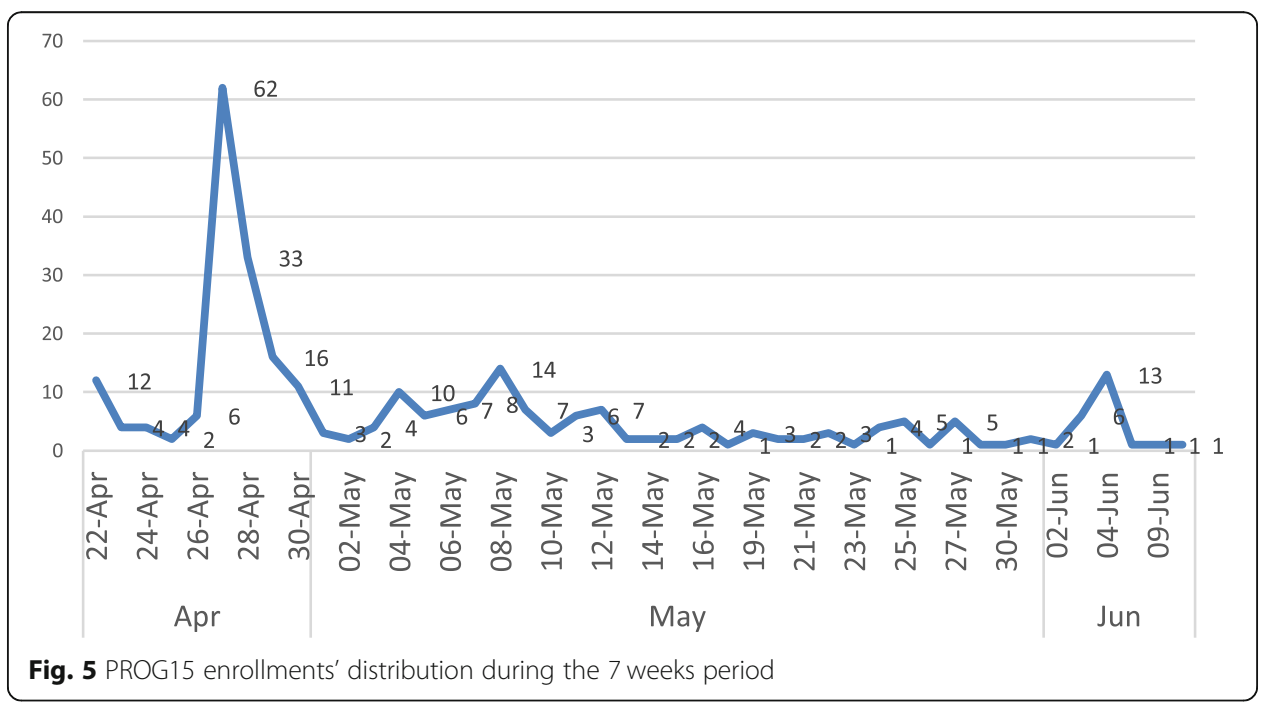


According to students' answers the most common reason for enrollment in PROG15 was their expectations for help and support to their "preparation for National exams in Computer Programming". More specifically, according to their open answers, some of the participating students wanted to deepen their understanding and achieve better results in national exams by their participation in PROG15, while others were looking for help and support on the difficulties they faced on their preparation for Computer Programming exams. Other reasons, apart from "Getting help and support for national exams", that students invoked for justifying their enrollment in PROG15 were "curiosity for this new learning tool", "preparation for final school exams", "for fun and because I am interested on Computer Programming" and finally "the instructor of the MOOC".

The above reasons and motives for MOOC enrollment and participation are very close to those that participants of higher education MOOCs invoke for their participation in MOOCs including acquisition or increase of knowledge, curiosity about the subject or about online courses, professional development, personal challenge, relevance to occupation or field of study, interest on the subject, fun and joy, institution that offers the course (Adamopoulos, 2013; Hew \& Cheung, 2014).

On the other hand, the most common reason according to the open students answers for early PROG15 drop-out was students' "lack of time".

The analysis of students' open-ended answers utilized elements from the Constant Comparison Analysis and Classical Content Analysis (Leech \& Onwuegbuzie, 2007) (Table 1).

\section{Students' completion and drop-out rates (the xMOOC dimension)}

Completion rate of a MOOC is the number of the registered students who fulfill the criteria of the course for the acquisition of a certificate of attainment (Jordan, 2014). These criteria (for example the kind and the number of activities) may vary from course to course while not all MOOCs offer a formal certificate of attainment. This criterion for PROG15 was the attendance of $75 \%$ of the provided video-lectures from the course. This threshold was chosen as the basic concepts of PROG15 (Lectures 6-28) represented the $80 \%$ of the total duration and some of these lectures could be omitted without any learning loss as many of the taught concepts were repeated in two different lectures.

According to the Udemy analytics platform, at the end of the PROG15, the majority of the 291 students (87.6\%) had covered less than half the course learning resources, $4.5 \%$ of the students covered more than half but less than $3 / 4$ of the course and only $7.9 \%$ of the students completed the course. It may seem that PROG15 completion rate

Table 1 Major reasons for enrollment and dropout

\begin{tabular}{ll}
\hline Major reasons for enrollment & $\begin{array}{l}\text { Major reasons for } \\
\text { dropout }\end{array}$ \\
\hline Getting help and support for national exams in Computer Programming (deepen & Lack of time \\
understanding on computer programming, achieve better results in national exams, get & \\
help and support on the difficulties faced) & \\
Curiosity for this new learning tool & Preparation for school exams \\
For fun and personal interest on Computer Programming & \\
For the instructor of the MOOC
\end{tabular}


is low, but it is similar to the completion rates of typical higher education MOOCs, which in most cases do not exceed 13\% (Jordan, 2014).

151 out of 291 (51.9\%) students that registered in PROG15 were "active" students. Active students, according to Jordan (2014), are those students that log-in to the MOOC a number of times, complete a quiz and/or watch a number of the provided video-lectures. The criterion for characterizing a student "active" in PROG15 was the attendance of at least 1.5 video-lectures, which equals to $5 \%$ of the total duration of the course. The remaining 140 out of the 291 registered students (48.1\%) were "inactive" students who either never logged-in to the course after their initial enrollment (100 students) or attended less than $5 \%$ of the provided video lectures and dropped out of the MOOC (40 students). This behavior is quite common according to Alario-Hoyos, Pérez-Sanagustín, Delgado-Kloos, and Munoz-Organero (2014) as many students after their registration and a quick preview of the offered educational resources realize that the specific course does not interest them and therefore drop out (Table 2).

If we exclude the 140 inactive PROG15 students from the analysis of the completion rates of PROG15, we will get the completion rates of only "active" students. In this case the percentage of completion of PROG15 rises up to a relatively satisfactory $15.2 \%$, while the percentage of the active students who attended more than half of the educational material approaches 24\% (Figs. 6 and 7).

Moreover, the Udemy analytics platform recorded for each one of the 31 video lectures of PROG15, the number of active students (a) who started and (b) managed to complete them. In Fig. 8 we placed these 62 values in the same diagram we and we got the general tendency of the percentage of the students who started and completed each one of the 31 video lectures. For example, in the following figure we can see that $47 \%$ of the active students started attending Lecture 1 but only $27 \%$ of the active students completed it, while $20 \%$ dropped out before ending it.

Furthermore, Fig. 8 shows that the number of students who started and managed to complete the video lectures of PROG15, demonstrates a downward trend from the first to the last video-lecture, a trend that is instantly reversed in the first Lecture of every new Section (Lectures 4, 6, 11, 14, 29) to return to its downward trend till the next Section. This instant increase of students' interest at the beginning of every new Section seems to be related to students' curiosity about the new content that may be entailed in this Section. So, for example the $36 \%$ of the active students who started the last Lecture of Section 1 (Lecture 5) rose to $53 \%$ in the first Lecture of the next Section which presented answers to questions of past national exams.

Table 2 Overall PROG15 enrollment, drop-out and completion rates

\begin{tabular}{lll}
\hline Participants & Number of students & \% of students \\
\hline Enrolled on PROG15 from 27/04/2015 until 14/06/2015 & 291 & $100 \%$ \\
Didn't access learning materials at all & 100 & $34.4 \%$ \\
Covered $>0 \%$ and $<6 \%$ of the learning materials & 40 & $13.7 \%$ \\
Covered $>5 \%$ and $<26 \%$ of the learning materials & 88 & $30.2 \%$ \\
Covered $>25 \%$ and $<51 \%$ of the learning materials & 27 & $9.3 \%$ \\
Covered $>50 \%$ and $<76 \%$ of the learning materials & 13 & $4.5 \%$ \\
Accessed $>75 \%$ of the learning materials & 23 & $7.9 \%$ \\
\hline
\end{tabular}




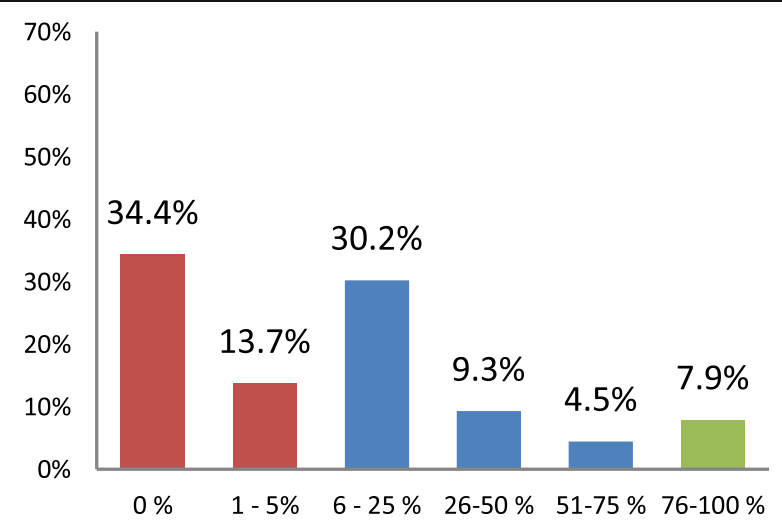

Fig. 6 distribution of \% completion $(n=291)$

Number of connections, pages per connection and bounce rate (the $x M O O C$ dimension)

During the seven-week running period of PROG15, Google Analytics platform recorded 2039 connections (sessions) with an average duration of $10 \mathrm{~min}$, a preview of 4,6 pages per connection and a bounce rate of approximately $40 \%$.

As it is demonstrated in Fig. 9, the number of connections per day fluctuates and this fluctuation seems to be linked

a. to the National exams dates: few sign-ins were recorded before the exam days for other courses (19th,21st of May and 3rd of June) and many connections before the exams on Computer Programming (the 5th of June) and some in the in between gap period (from the 21st of May till the 1st of June 2015)

b. to the dates of learning resources release: many sign-ins were recorded after the release of new Lectures (27th of April, 4th and 11th of May) and

c. to the advertising/promotion of PROG15: many sign-ins were recorded right after the initial promotional campaign (27/04) and some after the advertisement of PROG15 through emails to e-mailling list of computer science teachers (5th of May) and educational websites (10th of May).

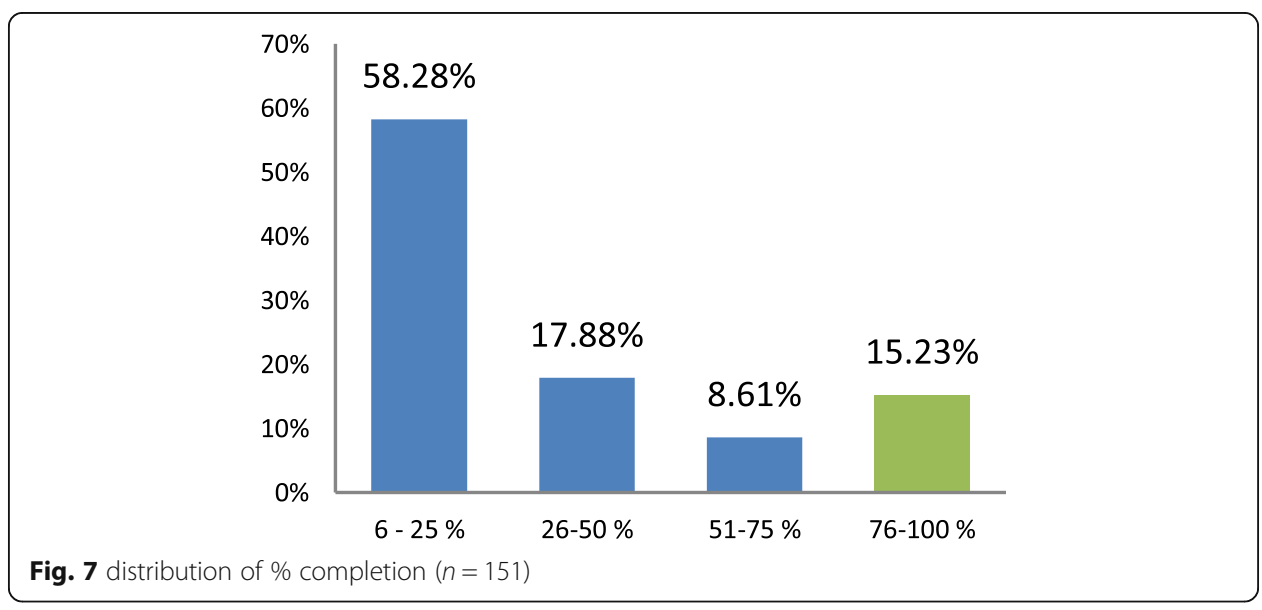




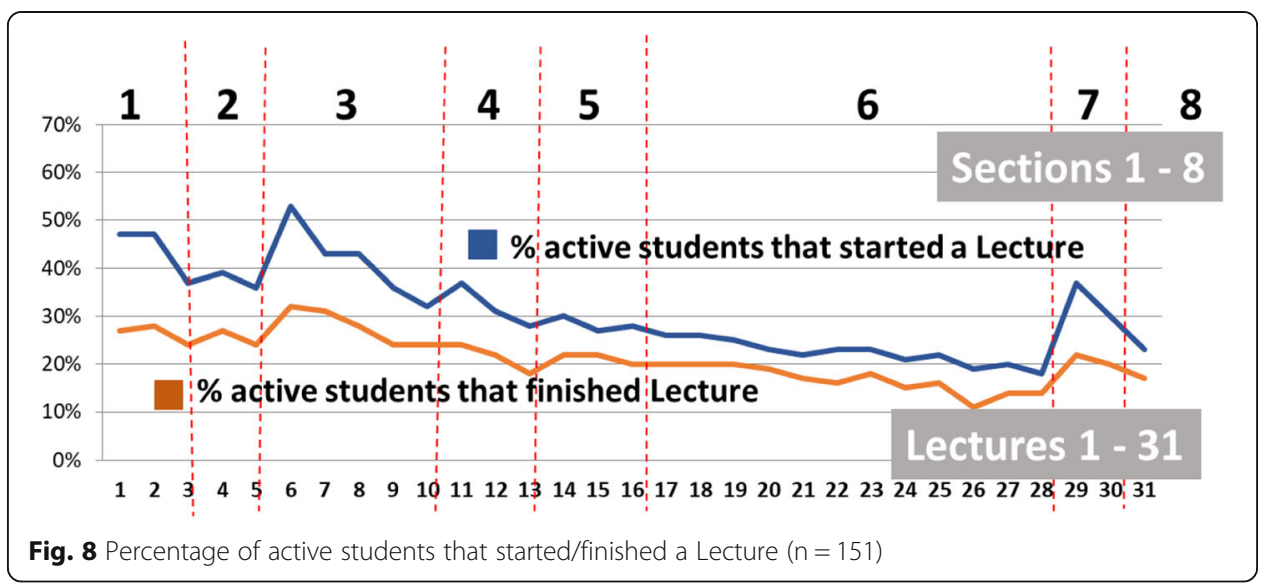

\section{Students' collaboration, interactions and contribution (the c-dimension)}

Students' interactions and contribution to the course content were observed and recorded for a period of 12 weeks. The observation period started from the launch of PROG15 and lasted until the 21st of July, that is 4 weeks after the announcements of students' scores on the national exams. During this period, a rather small number of interactions among PROG15 participants, as well as, quite low contribution to the course content through students' posts and comments on the Udemy and Facebook collaboration groups were recorded.

Participating students seemed to prefer Facebook Group than Udemy Q\&A Forum for communicating and sharing their contribution with their fellow students. More specifically, 24 (of the 151 active) students were involved in Udemy Q\&A Forum and uploaded 43 posts and 31 comments consisting of 2347 words in total. In the same period, 34 students (of the 151 active) were involved in the FB Group and uploaded 53 posts and 211 comments consisting of 4601 words in total while they reacted 189 times with "likes" to posts and comments of their fellow students. These activities of the FB Group were recorded on 22 out of the 88 days (25.6\%) of PROG15 provision. The most active days were the first days of PROG15 operation, the days approaching exams days, the days following new

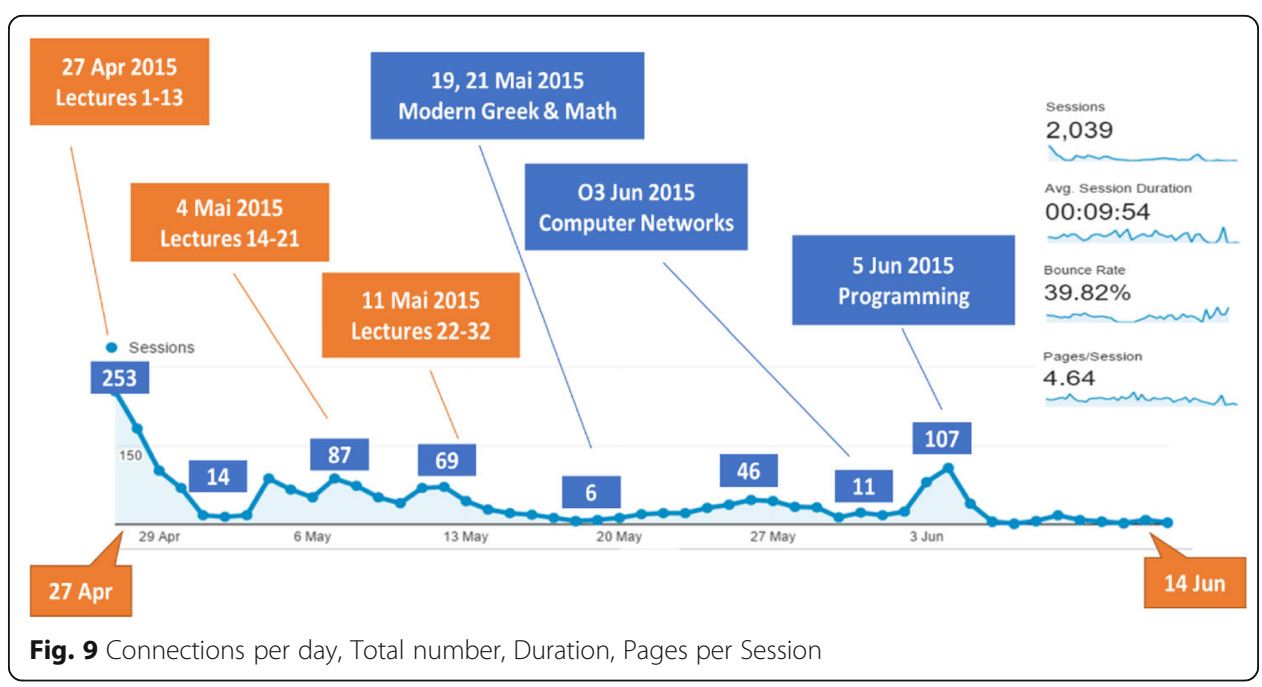


materials release and of course the days following the national exams results announcement (Fig. 10).

\section{Students' expectations, views and attitudes on PROG15 and MOOCs}

PROG15 students were invited to answer anonymously and voluntarily two electronic questionnaires one before and one after their participation in the MOOC. Out of the 151 active students, 46 answered the before-PROG15 and 22 the after-PROG15. Almost all of the participants (96\%) of both questionnaires were of the standard age of students of secondary education (<20 years old). 27 males (59\%) and 19 females $(41 \%)$ answered the before-PROG15 while 15 males $(68 \%)$ and 7 females $(32 \%)$ answered the after-PROG15.

Despite their little experience on MOOCs $(\mathrm{M}=2.4, \mathrm{SD}=1.20)$, most of the students who answered the before-PROG15 questionnaire recorded quite high learning expectations from their forthcoming participation in the MOOC, from the collaborative model that PROG15 proposed and from the potential adoption of MOOCs in secondary education (Table 3).

Most of the students who answered the after-PROG15 questionnaire had covered almost all the educational resources provided by PROG15, a fact that should be taken into consideration for potential positive prejudice towards the MOOC.

The quite positive results regarding students' expectations and attitudes on PROG15 and MOOCs before their involvement in PROG15, get even better taking into consideration students' answers regarding their overall experience from their participation in PROG15. Students' average score on this question was quite high $M=4.45$ with low variation $(\mathrm{SD}=0.67)$ and students seemed to enjoy the MOOC, with $91 \%$ of them stating that their overall experience was either very good (36.4\%) or even excellent (54.5\%) and none of them characterized their experience either poor or fair.

Additionally, students' familiarization with MOOCs after their involvement in PROG15 almost doubled, from a Mean of $\mathrm{M}=2.4$ (SD 1.20) in the before-PROG15 questionnaire to a Mean of $\mathrm{M}=4.32$ in the after-PROG15 questionnaire. Despite this quite impressive increase in their familiarization with MOOCs, students' contribution

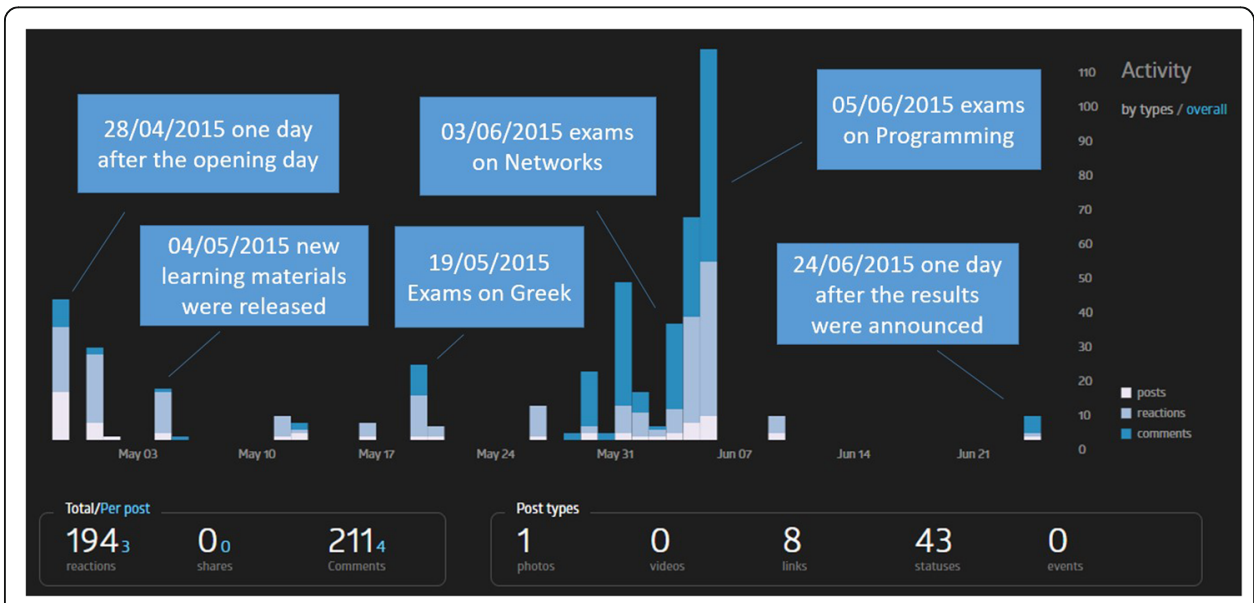

Fig. 10 Students' Comments \& Reactions to PROG15 resources (27/04-21.07/2015) 
Table 3 Students' responses in the before-PROG15 questionnaire $(\mathrm{N}=46)$

\begin{tabular}{|c|c|c|c|c|c|c|c|}
\hline Questions & Mean & SD & Not at & all ... Ex & xtremely & & \\
\hline How familiar are you with MOOCs? & 2.4 & 1.20 & $26.1 \%$ & $32.6 \%$ & $21.7 \%$ & $13 \%$ & $6.5 \%$ \\
\hline $\begin{array}{l}\text { How much will PROG } 15 \text { help you improve your knowledge } \\
\text { on Programming? }\end{array}$ & 3.8 & 0.72 & $0 \%$ & $2.2 \%$ & $30.4 \%$ & $52.2 \%$ & $15.2 \%$ \\
\hline $\begin{array}{l}\text { How much will the co-operation with your fellow students } \\
\text { help you improve your knowledge on Programming? }\end{array}$ & 3.6 & 0.80 & $0 \%$ & $8.7 \%$ & $34.8 \%$ & $45.7 \%$ & $10.9 \%$ \\
\hline $\begin{array}{l}\text { To what degree the adoption of MOOCs in teaching/ } \\
\text { learning process would positively affect secondary } \\
\text { education? }\end{array}$ & 4.1 & 0.94 & $0 \%$ & $6.5 \%$ & $19.6 \%$ & $32.6 \%$ & $41.3 \%$ \\
\hline
\end{tabular}

to the course resources and their interaction with their fellow students remained moderate ( $M=3.23, M=3.09$ respectively).

Moreover, after their involvement in PROG15 the majority of students that answered the after-PROG15 questionnaire believed that their participation in PROG15 (M $=4.32$, $\mathrm{SD}=0.78)$ as well as its collaborative learning model $(\mathrm{M}=4.09, \mathrm{SD}=0.87)$ had a positive impact on the knowledge they gained on programming and that the adoption of MOOCs in secondary education will have a positive effect on the educational process $(\mathrm{M}=4.32, \mathrm{SD}=0.78)($ Table 4$)$.

Finally, the after-PROG15 questionnaire included an open question which encouraged students to openly provide "any comment they wanted to". Nine students answered this open question and despite its open and non-directional nature, all of them commented on their positive experience from their participation in PROG15 and on the benefits they gained.

The analysis of students' open-ended answers utilized elements from the constant comparison analysis and classical content analysis (Leech \& Onwuegbuzie, 2007). The analysis of students' answers revealed (a) students' strong belief that their participation in PROG15 helped and supported them in learning computer programming (b) students' positive attitude about the course and gratitude for the instructor and (c) students' friendly, humorous and relaxed language, mood and style of writing.

More specifically, the analysis of students' answers identified 14 references to the help and support students received by the course and / or the instructor, either by the direct use of word "help" or by the indirect use of terms that imply help and / or support. For

Table 4 Students' responses after-PROG15 ( $N=22)$

\begin{tabular}{|c|c|c|c|c|c|c|c|}
\hline Questions & Mean & SD & Not a & t all & Extreme & & \\
\hline What percentage of the course did you attend? & 4.14 & 1.31 & $45 \%$ & $4.5 \%$ & $22.7 \%$ & $9.1 \%$ & $59.1 \%$ \\
\hline How familiar are you with MOOCs? & 4.32 & 0.72 & $0 \%$ & $0 \%$ & $13.6 \%$ & $40.9 \%$ & $45.5 \%$ \\
\hline How much did you contribute to the course resources? & 3.45 & 1.37 & $9.5 \%$ & $19 \%$ & $23.8 \%$ & $19 \%$ & $28.6 \%$ \\
\hline How much did you interact with your fellow students? & 3.09 & 1.27 & $9.1 \%$ & $27.3 \%$ & $27.3 \%$ & $18.2 \%$ & $18.2 \%$ \\
\hline $\begin{array}{l}\text { To what degree did PROG } 15 \text { help you improve your } \\
\text { knowledge on Programming? }\end{array}$ & 4.32 & 0.78 & $0 \%$ & $0 \%$ & $18.2 \%$ & $31.8 \%$ & $50 \%$ \\
\hline $\begin{array}{l}\text { To what degree did your interaction with your fellow } \\
\text { students help you improve your knowledge on } \\
\text { Programming? }\end{array}$ & 4.09 & 0.87 & $0 \%$ & $4.5 \%$ & $18.2 \%$ & $40.9 \%$ & $36.4 \%$ \\
\hline $\begin{array}{l}\text { To what degree the adoption of MOOCs in teaching/learning } \\
\text { process would positively affect secondary education? }\end{array}$ & 4.32 & 0.78 & $0 \%$ & $0 \%$ & $18.2 \%$ & $31.8 \%$ & $50 \%$ \\
\hline How would you evaluate your overall experience? & 4.45 & 0.67 & $0 \%$ & $0 \%$ & $9.1 \%$ & $36.4 \%$ & $54.5 \%$ \\
\hline
\end{tabular}


example, a student stated that "it [PROG15] helped me better understand programming and solve questions and queries I had", while another student "I used PROG15 for revision and it helped me a lot" and two more students "the video lectures I were very good and helped me a lot".

Some students personalized the help and support they got from PROG15 to the instructor "You helped me so much, thank you..." or "I wish that other teachers will help students the same way you did with us ..." or "the work you have done shows that there are teachers out there who really care about the students". As a result, in many cases students commented very positively about the instructor "I wish you the very best, be well so that you will be able to help more children like me in the future that face difficulties in programming and have gaps in their knowledge ... ". In some cases, students, in an attempt to further strengthen their positive comments and gratitude to the instructor they accompanied their answers using capital letters, many emotion icons and punctuation symbols: "THANK YOU VERY MUCH!!!!! I HOPE THAT YOU WILL KEEP UP THE GOOD WORK!!?", "You did a great job: )))", "You and your efforts for developing the MOOC were perfect: )", "be well!!?".

Two students reported that the MOOC has stimulated their self-confidence "[PROG15 in general] made me feel more confident on what I am doing and, on the problems and assignments I solve" and "it helped me believe in myself".

Two students commented on the positive impact that the pleasant nature of PROG15 had on the learning process. One of them characterized MOOCs as "a means to escape from the everyday school- life that makes learning easier and fun" while the other believed that "they [MOOCs] should be utilized in education because they make learning more enjoyable, entertaining and easier".

A rather interesting comment was made from a group of students from a school in Northern Greece which claimed that "PROG15 helped not only the students that aimed to achieve high scores on national exams for entering a University but also students that didn't have this purpose ... ".

The last two comments reveal that students which have been left behind and students with low motives and low self-esteem feel that PROG15 supported them in their attempts to understand computer programming and eventually in their preparation for national exams. These comments reveal a potential for MOOCs on supporting low-performing students.

Finally, contrary to the rather formal style of writing that students utilized in their before-MOOC answers, their after-MOOC answers were quite informal, humorous, warm and friendly, resembling in some cases friendly social-media chats. For example, a student, in the question that asked him to provide freely any comment wrote: "I'm hungry, it's 4 o clock in the morning and I'm solving programming problems!!! Very nice all the lectures and exercises, they helped me a lot, but I wish they talked about theory too, you see I try to read theory of HYPO diagrams [a diagram type of Pascal] and the only thing that comes to my mind are hippopotami". Another student, in the same question, made a positive but humorous comment about the instructor saying "You are cool ... ". Finally, a third student stated: "Although I don't know you personally I feel that the video lectures developed an intimacy and a certainty to what I hear...".

\section{Discussion and conclusions}

During PROG15 research cycle, a preparatory for national exams computer programming MOOC for Greek secondary education was designed, developed, implemented 
and openly provided for a period of 7 weeks, from April to June 2015. The MOOC achieved to attract the $12.2 \%$ of the Greek vocational high-school students who were preparing to participate in national exams on computer programming, for entering Greek higher educational institutes.

Within the context of a participatory action research, students' learning analytics data were collected for a period of 7 weeks and analyzed, as well as their motives for enrollment, learning expectations, attitudes, assessments, overall experience and reasons for early MOOC dropout.

\section{Enrollment, completion and dropout rates}

According to students' answers the main reason for enrolling in PROG15 was to "acquire or increase knowledge on computer programming", as students were looking for help and support for their "preparation for national exams". On the other hand, the main reason for not completing the course was the "lack of time", while many students decided to selectively watch only the video-lectures in which they were interested in.

Students' learning analytics data revealed a rather low overall completion rate, but similar to the completion rate of typical MOOCs for older students, ranging from $8 \%$ to $15.2 \%$, depending on the inclusion (or not) of inactive students. Almost half of the enrolled students either never logged on the course after their enrollment, or covered less than $5 \%$ of the provided learning materials.

A downward trend regarding video-lectures' start and completion rates was revealed as time passed. Every time a new section was offered in the MOOC platform this trend was instantly reversed by students who decided to attend selectively only the lectures in which were interested in.

Additionally, the number of sessions and new sessions, as well as the average time students spent on PROG15 per day, were directly affected by external factors, all of them related to students' available time for study.

\section{Collaboration / interaction and contribution to the course content}

PROG15 students could interact/collaborate with their fellow students and contribute to PROG15 learning resources in both Udemy forum and Facebook group. Their contribution to PROG15 content was rather poor with less than 2 posts per student on average, while their collaboration/interaction with their fellow students was poor too, with every PROG15 student having less than 6 interactions with their fellow students on average.

\section{Students' expectations, experience and attitudes towards PROG15 \& MOOCs}

Despite students' low degree of contribution to the PROG15 content and the low degree of interaction with their co-MOOCers, the analysis of their before- and afterPROG15 answers revealed students' very positive view for MOOCs, for their pedagogical approach, for the communication and collaboration opportunities they provide, for their help and support and for the potential learning benefits from their adoption in secondary education.

Most of the enrolled students assessed very positively their overall experience with PROG15, feel very comfortable and familiar with MOOCs after their involvement in PROG15, strongly believe that the utilization of MOOCs in secondary education will have 
a quite positive impact on the educational process, strongly believe that PROG15 and the collaborative learning model it proposed had a positive impact on the knowledge they gained and on their preparation for national exams on Computer Programming.

Most of the enrolled students, who provided answers to the before-MOOC questionnaire, held quite high expectations regarding the benefits from their participation in PROG15 and consequently regarding the impact on their performance on national exams. These quite high expectations were fully realized, at least for the students that provided answers for the after-MOOC questionnaire, who claimed that their involvement in the MOOC, supported and helped their preparation for the exams in many ways (increased confidence, supported revision, answered questions, covered learning gaps, helped them learn and better understand programming).

After their involvement in PROG15, student see MOOCs as a "pleasant and entertaining way of learning", "a way to escape from everyday school routine" and "a tool that makes learning easier and more fun". Moreover, some students believe that MOOCs "can help low performing students as well as students with learning gaps that have been left behind", due to their self-paced nature and propose their introduction into secondary education as self-paced cram schools for reinforcing teaching and learning.

Students in their after-PROG15 answers utilized a quite informal, humorous, warm and friendly language and style, reminding in some cases friendly social-media chats.

These findings, although requiring further investigation, form a particularly promising background for the utilization of this new tool in secondary education, in general, and specifically in the preparation of students for higher education.

\section{Future research}

Aiming to further investigate the field, during the succeeding school period (2015-16) a new version of PROG15 MOOC was designed, implemented and offered to Greek Vocational school students. This new MOOC (named PROG16) was designed and implemented taking into consideration the positive conclusions and the open issues that required further investigation, as these resulted from the analysis of PROG15 MOOC.

In this respect PROG16 MOOC was decided to:

- be available for a longer period (9.5 weeks +1 promotional week)

- include shorter video-lectures and a more simplified syllabus structure

- provide ubiquitous access to students (anytime, anywhere) giving them the ability to access the MOOC platform from their mobile devices

- provide more refined and focused questionnaires, better positioned in the research design, aiming to collect more answers

- enhance and promote the collaborative learning community by introducing nine open plenary meetings in the Facebook group with the active participation of the instructor

- involve past (PROG15) students, as well as additional computer science teachers, as PROG16 facilitators and instructors

- explore whether students with diagnosed learning disabilities participated in PROG16 and attempted to record and analyze their motives for participation and reasons for early dropout, learning expectations and attitudes on MOOCs 
We believe that the analysis of the results of PROG16 and their correlation to those of PROG15 will form a valuable research background for further research regarding the exploitation of MOOCs in secondary education. Additionally, we expect the research outcomes of our work to disseminate the idea of MOOCs in K-12 education, to identify the ideal conditions and pre-requisites and to propose a set of good practices and procedures for their introduction and utilization in secondary education schools.

We also expect that research initiatives like this one will trigger, stimulate the interest and actively involve in the case of K-12 MOOCs both the educational researchers and the actors involved in the design and development of Greek educational policy, especially those dealing with the introduction and the utilization of new educational technological tools, for the preparation of an official framework for MOOCs' utilization and establishment in Greek secondary education.

Finally, we believe that research efforts like this will result in an increased demand, utilization and creation of K-12 MOOCs, which will in turn lead to further research and experimentation. The outcomes of such research can further improve and enrich K-12 MOOCs in order to meet higher quality levels, be more tempting to the interests and preferences of young learners and further assist and improve teaching and learning.

Acknowledgements

Not applicable.

\section{Authors' contributions}

PK and CK conceived the study, PK carried out the design, implementation provision and analysis of the PROG15 MOOC and drafted the manuscript. PP, EK and CK participated in the design of the study and the overall analysis of the results and helped to draft the manuscript. All authors read and approved the final manuscript.

Funding

Not applicable.

Availability of data and materials

The datasets used and/or analyzed during the current study are available from the corresponding author on reasonable request.

\section{Competing interests}

The authors declare that they have no competing interests.

\section{Author details}

${ }^{1}$ Department of Special Education, University of Thessaly, Volos, Greece. ${ }^{2}$ Department of Primary Education, Volos, Greece. ${ }^{3}$ Department of Early Childhood Education, University of Thessaly, Volos, Greece.

Received: 15 October 2019 Accepted: 8 January 2020

Published online: 04 March 2020

References

Adamopoulos, P. (2013). What makes a great MOOC? An interdisciplinary analysis of student retention in online courses. In Milan: Proceedings of the 34 th international conference on information systems.

Alario-Hoyos, C., Pérez-Sanagustín, M., Delgado-Kloos, C., \& Munoz-Organero, M. (2014). Delving into participants' profiles and use of social tools in MOOCs. IEEE Transactions on Learning Technologies, 7(3), 260-266.

Atkeson, S. (2014). Harvard-MIT partnership unveils new MOOCs for K-12. Education Week, 34(5), 8 Retrieved from http://goo. $\mathrm{gl} / \mathrm{s} 1 \mathrm{Q} 049$.

Balanskat, A., \& Engelhardt, K. (2014). Computing our future. Computer programming and coding. Priorities, school curricula and initiatives across Europa. Belgium: European Schoolnet Retrieved from http://shorturl.at/cdeh4.

Bali, M. (2013). 5 reasons teachers should dip into MOOCs for professional development. In MOOC news \& reviews Retrieved October 6, 2018 from https://bit.ly/2pNozY4.

Bayne, S., \& Ross, J. (2014). The pedagogy of the massive open online course: The UK view. York: The Higher Education Academy Retrieved from https://www.heacademy.ac.uk/resources/detail/elt/the_pedagogy_of_the_MOOC_UK_view.

Ben-Ari, M. (2013). MOOCs on introductory programming: A travelogue. ACM Inroads, 4(2), 58-61.

Brahimi, T., \& Sarirete, A. (2015). Learning outside the classroom through MOOCs. Computers in Human Behavior, 51, 604-609 https://doi.org/10.1016/j.chb.2015.03.013.

Briggs, S., \& Crompton, H. (2016). Taking advantage of MOOCs in k-12 education: A blended approach. In Mobile and blended learning innovations for improved learning outcomes (pp. 297-309). IGl Global. 
Canessa, E., \& Pisani, A. (2013). High school open on-line courses (HOOC): A case study from Italy. European Journal of Open, Distance and e-learning, 16(1) https://www.eurodl.org/materials/contrib/2013/Canessa_Pisani.pdf.

Class Central. (2019a). By the numbers: MOOCs in 2019 https://www.classcentral.com/report/mooc-stats-2019/.

Class Central. (2019b). Class Central's top 100 MOOCs of all time (2019 edition) https://www.classcentral.com/report/topmoocs-2019-edition/.

Conole, G. (2013). MOOCs as disruptive technologies: Strategies for enhancing the learner experience and quality of MOOCs. E-Lis Retrieved on 8 June 2016 from http://eprints.rclis.org/19388/.

Conole, G. (2014). A new classification schema for MOOCs. The International Journal for Innovation and Quality in Learning, 2(3), 65-77.

Dal Magro, E., Gebing, S., Heinzmann, L., Romagna, M. E., Studer, J., Goulart, T. M., \& Imran, H. (2017). MOOC as supplementary tutoring to public school students learning. In 2017 IEEE 17th International Conference on Advanced Learning Technologies (ICALT) (pp. 220-223). IEEE.

De Kereki, I. F., \& Manataki, A. (2016). "Code yourself" and "a programar": A bilingual MOOC for teaching computer science to teenagers. In 2016 IEEE Frontiers in education conference (FIE) (pp. 1-9). IEEE.

Downes, S. (2008). Places to go: Connectivism \& connective knowledge. Innovate: Journal of Online Education, 5(1), 6.

Dziabenko, O., \& Adorno, D. P. (2017). Application of remote experiments in a secondary school using MOOC approach. In 2017 4th experiment@ international conference (exp.at'17) (pp. 191-195). IEEE.

Ebben, M., \& Murphy, J. S. (2014). Unpacking MOOC scholarly discourse: A review of nascent MOOC scholarship. Learning. Media and Technology, 39(3), 328-345.

EdX. (2018). Get college ready. Get ahead. Get learning! Retrieved August 20, 2018 from https://www.edx.org/high-school.

Ferdig, R. E. (2013). What massive open online courses have to offer $K-12$ teachers and students. Michigan Virtual Learning Research Institute Retrieved from http://media.mivu.org/institute/pdf/mooc_report.pdf.

Ferdig, R. E., Pytash, K. E., Merchant, W., \& Nigh, J. (2014). Findings and reflections from the K-12 teaching in the 21st century MOOC. Lansing: Michigan Virtual Learning Research Institute Retrieved from http://media.mivu.org/institute/pdf/MOOC_ Findings.pdf.

Fidalgo-Blanco, Á., Sein-Echaluce, M. L., \& García-Peñalvo, F. J. (2016). From massive access to cooperation: Lessons learned and proven results of a hybrid XMOOC/CMOOC pedagogical approach to MOOCs. International Journal of Educational Technology in Higher Education, 13(1), 24.

Filvà, D. A., Guerrero, M. J. C., \& Forment, M. A. (2014). The effects of massiveness on the participation in social technologies: A MOOC in secondary education. In Proceedings of the second international conference on technological ecosystems for enhancing Multiculturality (pp. 397-402). ACM.

FutureLearn. (2018). FutureLearn for schools Retrieved August 8, 2018 from https://www.futurelearn.com/schools.

García-Peñalvo, F. J., Fidalgo-Blanco, Á., \& Sein-Echaluce, M. L. (2018). An adaptive hybrid MOOC model: Disrupting the MOOC concept in higher education. Telematics and Informatics, 35(4), 1018-1030.

Greek Ministry of Education. (2015a). Course syllabus of computer programming for Greek vocational schools. Athens: Greek Ministry of Education Retrieved June 6, 2016 from http://www.pichools.gr/download/lessons/tee/computer/PS/ PROGRAMMATISMOS.ZIP.

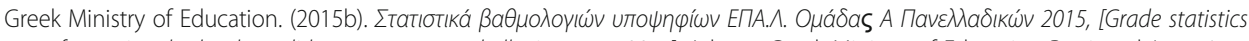
of vocational school candidates group a panhellenic exams 2015]. Athens: Greek Ministry of Education Retrieved June 6 , 2016 from http://www.minedu.gov.gr/grafeio-typoy-kai-dimosion-sxeseon/deltia-typoy/13650-25-06-2015-2015.

Grella, C., Staubitz, T., Teusner, R., \& Meinel, C. (2016). Can MOOCs support secondary education in computer science? In International conference on interactive collaborative learning (pp. 478-493). Cham: Springer.

Grover, S., Pea, R., \& Cooper, S. (2014, March). Promoting active learning \& leveraging dashboards for curriculum assessment in an OpenEdX introductory CS course for middle school. In Proceedings of the first ACM conference on Learning@ scale conference, 205-206. ACM.

Guzdial, M., \& Adams, J. (2014). MOOCs need more work; so do CS graduates. Communications of the ACM CACM, 57(1), 1819.

Hew, K. F., \& Cheung, W. S. (2014). Students' and instructors' use of massive open online courses (MOOCs): Motivations and challenges. Educational Research Review, 12(1), 45-58.

Holotescu, C., Grosseck, G., Cretu, V., \& Naaji, A. (2014). Integrating MOOCs in blended courses. Bucharest: Proceedings of the International Scientific Conference of eLearning and Software for Education.

Jacoby, J. (2014). The disruptive potential of the massive open online course: A literature review. Journal of Open, Flexible and Distance Learning, 18(1), 73-85.

Jordan, K. (2014). Initial trends in enrolment and completion of massive open online courses. The International Review of Research in Open and Distributed Learning, 15(1), 133-160.

Kaplan, A. M., \& Haenlein, M. (2016). Higher education and the digital revolution: About MOOCs, SPOCs, social media, and the cookie monster. Business Horizons, 59(4), 441-450.

Kemmis, S., \& McTaggart, R. (1992). The action research planner (3rd ed.). Geelong: Deakin University Press.

Kennedy, J. (2014). Characteristics of massive open online courses (MOOCs): A research review, 2009-2012. Journal of Interactive Online Learning, 13(1), 1-16.

Kesim, M., \& Altınpulluk, H. (2015). A theoretical analysis of Moocs types from a perspective of learning theories. Paper presented at 5th world conference on learning, teaching and educational leadership (WCLTA 2014). https://doi.org/10.1 016/j.sbspro.2015.04.056.

Khalil, M., \& Ebner, M. (2015). A STEM MOOC for school children-What does learning analytics tell us? In 2015 International Conference on Interactive Collaborative Learning (pp. 1217-1221). Florence: IEEE.

Kilde, J., Bennett, J. K., Gonzales, L., \& Sterling, S. (2013). A connective massive open online course for K-12 science, technology, engineering, and mathematics teachers in New Mexico Pueblo schools. In Proceedings of the sixth international conference on information and communications technologies and development: Notes-volume 2 (pp. 61-64). ACM.

Koutsakas, P. (2018). Massive open online courses (MOOCs) in Greek secondary education: Exploring the potential role, values, uses and prospects of MOOCs in Greek secondary education for typical students and students with diagnosed special 
learning disabilities (Doctoral dissertation). Volos: University of Thessaly Retrieved from https://phdtheses.ekt.gr/eadd/ handle/10442/45338.

Koutsakas, P., Syritzidou, E., Karamatsouki, A., \& Karagiannidis, C. (2019). Exploring the Role of Facebook as Collaboration Platform in a K-12 MOOC. In M. Tsitouridou, J. A. Diniz, \& T. Mikropoulos (Eds.), Technology and Innovation in Learning, Teaching and Education. TECH-EDU 2018. Communications in Computer and Information Science (Vol. 993). Cham: Springer.

Koxvold, I. (2014). MOOCs: Opportunities for their use in compulsory-age education (research report). Darlington: UK Department of Education.

Leech, N. L., \& Onwuegbuzie, A. J. (2007). An array of qualitative data analysis tools: A call for qualitative data analysis triangulation. School Psychology Quarterly, 22, 557-584.

Liyanagunawardena, T. R., Adams, A. A., \& Williams, S. A. (2013). MOOCs: A systematic study of the published literature 20082012. The International Review of Research in Open and Distributed Learning, 14(3), 202-227.

Najafi, H., Evans, R., \& Federico, C. (2014). MOOC integration into secondary school courses. The International Review of Research in Open and Distributed Learning, 15(5), 307-322.

Nigh, J., Pytash, K. E., Ferdig, R. E., \& Merchant, W. (2015). Investigating the potential of MOOCs in K-12 teaching and learning environments. Journal of Online Learning Research, 1(1), 85-106.

O'Brien, R. (2001). An overview of the methodological approach of action research. In R. Richardson (Ed.), Theory and practice of action research. João Pessoa: Universidade Federal da Paraíba Available online at http://www.web.ca/ robrien/papers/ arfinal.html. Accessed on 12 June 2010.

Pilli, O., \& Admiraal, W. (2016). A taxonomy for massive open online courses. Contemporary Educational Technology, 7(3), 223240.

Siemens, G. (2012). Designing and running a MOOC in 9 easy steps. Designing, developing and running (massive) open online courses. Retrieved from http://www.elearnspace.org/blog/2012/09/04/designing-and-running-a-mooc-in-9-easysteps/.

Staubitz, T., Teusner, R., \& Meinel, C. (2019). MOOCs in secondary education-experiments and observations from German classrooms. In 2019 IEEE global engineering education conference (EDUCON) (pp. 173-182). IEEE.

Yin, Y., Adams, C., Goble, E., \& Madriz, L. F. V. (2015). A classroom at home: Children and the lived world of MOOCs. Educational Media International, 52(2), 88-99 https://doi.org/10.1080/09523987.2015.1053287.

\section{Publisher's Note}

Springer Nature remains neutral with regard to jurisdictional claims in published maps and institutional affiliations.

\section{Submit your manuscript to a SpringerOpen ${ }^{\circ}$ journal and benefit from:}

- Convenient online submission

- Rigorous peer review

- Open access: articles freely available online

- High visibility within the field

- Retaining the copyright to your article

Submit your next manuscript at $\boldsymbol{\nabla}$ springeropen.com 